\title{
Resenha
}

\section{ENSAIOS DE SOCIOLOGIA DA CIÊNCIA: MAIS QUE UMA COLETÂNEA, UM MAPA DA VISÃO MERTONIANA SOBRE CIÊNCIA}

Gabriel Bandeira Coelho. Mestre em Sociologia pela Universidade Federal de Pelotas (2015). Professor do Instituto de Ciência Tecnologia IFSUL Campus/Pelotas.

Guilherme Camargo Massaú. Professor no Curso de Direito e no Mestrado em Sociologia da UFPEL.

Resenha da Obra: MERTON, Robert. Ensaios de sociologia da ciência. São Paulo: Editora 34, 2013.

A coleção de textos do sociólogo norte americano Robert Merton, intitulada "Ensaios de sociologia da ciência”, organizada por Anne Marcovich e Terry Shinn, publicada em 2013 pela Editora 34, em São Paulo, traz uma importante contribuição para alunos, professores e pesquisadores que se interessam pela sociologia do conhecimento e da ciência, bem como, pela intensa reflexão acerca da relação entre ciência e sociedade. Além disso, muito colabora para se entender como se deu o processo de institucionalização da Ciência e como funciona a natureza e o ethos científico.

A presente obra está dividida da seguinte forma: Parte 1, com o título "Fatores externos do surgimento e desenvolvimento da ciência", dividida em mais três capítulos, quais sejam: "Puritanismo, pietismo e ciência"; "A ciência e a técnica militar" e "Influências extrínsecas à pesquisa científica"; a Parte 2, intitulada "Dos ombros de gigantes a estímulos e armadilhas cognitivas", divide-se em três capítulos: "A sociologia do conhecimento (1937)"; “A sociologia do conhecimento (1945)" e "A ciência e a ordem social”; por fim, a Parte 3, chamada de "A estruturação da comunidade científica e a dinâmica social da tecnologia", divida em três capítulos; "A ciência e a estrutura social democrática"; "Efeito Mateus na 
ciência II: a vantagem cumulativa e o simbolismo da propriedade intelectual" e "A máquina, o trabalhador e o engenheiro".

Conforme aponta Garcia (2013), tradutora da obra, a emergência desta reunião de textos dá-se pela dificuldade, no Brasil, de acesso aos diversos escritos seminais de Merton, que é, sem dúvida, uma figura central da sociologia produzida nos Estados Unidos. Segundo argumentam Marcovich e Shinn (2013, p. 253), "Merton dominou o campo da sociologia da ciência até a publicação do livro 'A estrutura das revoluções científicas', de Thomas Kuhn, e do surgimento do Programa Forte de sociologia na década de 1970"1.

Identifica-se que a presente obra destaca um dos aspectos mais relevantes da teoria mertoniana: sua visão externalista de ciência, ou seja, uma perspectiva que aponta a produção de conhecimento científico, a relação entre ciência e sociedade, como resultante do reflexo social e do contexto cultural. Por conseguinte, conhecimento e ciência são pilares da estrutura dessa sociedade que surge após a Segunda Guerra Mundial (WELSCH, 2002, p. 26).

No primeiro capítulo, intitulado "Puritanismo, pietismo e ciência" - 1936 -, Merton salienta o surgimento e a consolidação da Royal Society of London, na Ingleterra do século XVII, demonstrando o ímpeto do éthos puritano para com a ciência. Merton (2013) destaca que o puritanismo esteve fortemente relacionado ao despertar do interesse na ciência durante o século XVII, período esse de grande efervescência da filosofia moderna. Essa característica era muito associada ao viés realista e utilitário protestante de conceber o mundo. Merton ressalta ainda a tendência puritana para o progresso científico, destacando o contraste entre os ensinamentos das escolas (academias) católicas com as puritanas e pietistas, afirmando que “embora na população total existissem mais do que três vezes mais católicos do que protestantes, existiam mais cientistas protestantes do que católicos" (MERTON, 2013, p. 46).

No segundo capítulo, denominado “A ciência e técnica militar" - 1938 -, Merton (2013) - partindo novamente da Inglaterra, líder militar e comercial do século XVII - aponta para fatores militares que colaboraram/influenciaram o desenvolvimento do conhecimento científico. Não obstante, Merton ressalta que cientistas clássicos também reuniram alguns esforços no que concerne à solução de problemas da técnica militar, relacionados à balística. Por conseguinte, Merton conclui que as necessidades resultantes da tecnologia militar,

\footnotetext{
${ }^{1}$ Posteriormente, a partir da década de 70, o debate tornou-se mais acirrado nos âmbitos da Sociologia e da Antropologia, com os agora chamados Science Studies, e suas diferentes abordagens (observacionais, construtivistas, linguísticas etc.), desenvolvidas por autores, tais como: David Bloor; Barry Barnes; Peter Slezak; Sergio Simon; Karin Knorr-Cetina; Bruno Latour; Steve Woolgar; Harry Collins e Trevor Pinch, e têm se estendido até os dias de hoje.
} 


\section{Ensaios de sociologia da ciência: mais que uma coletânea, um mapa da visão mertoniana sobre ciência}

certamente influenciaram os olhares da ciência, sublinhando, dessa forma, a centralidade dos fatores extrínsecos -dimensão dos aspectos sociais que influenciam a produção de ciência -, no que tange ao interesse e ao progresso científico.

Com base nas atas da Sociedade Real, no terceiro capítulo, intitulado "Influências extrínsecas à pesquisa científica" - 1938 - Merton (2013) destaca os principais fatores que influenciaram o desenvolvimento da ciência na Sociedade Real. Com dados e estatísticas, o autor destaca que as necessidades socioeconômicas refletiram na escolha dos temas que seriam investigados na Inglaterra do século XVII. Nesse sentido, salienta que entre $30 \%$ e $60 \%$ das pesquisas deste período foram influenciadas, direta ou indiretamente, por fatores econômicos. Para o autor, há seis classes de fatores externos que influenciaram a ciência neste período, quais sejam: a vida econômica, a guerra, a medicina, as artes, a religião e a busca desinteressada pela verdade.

Já em "A sociologia do conhecimento" - 1937 - título do quarto capítulo, Merton ressalta elementos que definem a sociologia do conhecimento, bem como as contribuições de Max Scheler e Karl Mannheim para esta nova área da sociologia, característica da primeira metade do século XX. Ademais, ele traz elementos críticos de Von Schelting às concepções de Mannheim. Neste capítulo, Merton argumenta que a sociologia do conhecimento, enquanto nova disciplina à época, desenvolvia-se por meio de vários estudantes e intelectuais e de uma crescente bibliografia sobre o tema.

Tendo como base o objetivo de mostrar que a ciência desenvolve-se por meio de condições externas a ela, Merton ressalta os argumentos de Scheler, salientando que um dos fatores que influenciaram a emergência da ciência moderna, foi a dissociação, a ruptura entre o Estado e a Igreja e a multiplicação de seitas religiosas. Segundo Merton (2013, p. 98), "isso significou uma garantia ainda maior para a liberdade da ciência, pois os cientistas puderam jogar as muitas autoridades umas contra as outras". Não obstante, o autor afirma também que para Scheler, a democracia parlamentar esteve, de fato, relacionada ao desenvolvimento da ciência no período liberal, por meio de um conjunto de interesses e demandas em comum.

Segundo Merton, Mannheim argumenta - a partir de seu exame sobre o pensamento humano (conhecimento) - que o conhecimento está profundamente relacionado a um meio social. Característica essa que demonstra a dimensão externalista de ciência presente nesta época $(1920,1930)$, bem como, uma dimensão hermenêutica e também historicista em 
Mannheim, haja vista o contexto de produção intelectual alemão que ele estava inserido nas primeiras décadas do século XX.

No quinto capítulo, também intitulado de "Sociologia do conhecimento" - 1945 Merton (2013, p. 109) mantém a definição da disciplina (sociologia do conhecimento) afirmando que "ela concerne principalmente às relações entre conhecimento e outros fatores existenciais na sociedade ou da cultura". O autor destaca o contexto social de emergência da sociologia do conhecimento, enquanto disciplina distinta, mostrando que a mesma teve grande florescimento na Alemanha e na França e somente depois, a partir de 1930, passou a ser percebida no cenário intelectual norte-americano. Merton sublinha que o aumento de conflitos sociais e das diferenças de valores fez com que a orientação em comum que se mantinha entre os diversos grupos, acabaram enfraquecidas por diferenças incompatíveis. Assim, Merton (2013, p. 111) salienta que "em um contexto de desconfiança não se pergunta sobre o conteúdo das crenças e asserções para determinar se são válidas ou não (...) mas é introduzida uma questão nova: como pode acontecer que essas visões se mantenham?”.

Com efeito, destaca-se a proposta mertoniana de um paradigma para a sociologia do conhecimento, enquanto projeto de análise e base de comparação para esquematizar os estudos que se concentram neste campo. Neste sentido, Merton (2013, p. 116-117) expõe os seguintes questionamentos: a) onde está localizada a base existencial das produções mentais? b) quais são as produções mentais sociologicamente analisadas? c) Como as produções mentais relacionam-se com a base existencial? d) por que funções latentes e manifestas são imputadas a essas produções mentais existencialmente condicionadas? e) quando se estabelecem as relações imputadas à base existencial e ao conhecimento?

No sexto capítulo, "A ciência e a ordem social” - 1938 -, Merton destaca a importância da ciência em contextos culturais definidos e o valor que esse contexto atribui à verdade científica, que não é absoluta, pois traz junto a essa crença, a dúvida e a descrença. A ciência desenvolve-se com grau de consistência conforme as estruturas - que a partir de mudanças podem interromper, modificar ou impedir o desenvolvimento científico $-\mathrm{e}$ a participação ativa dos indivíduos interessados nos objetivos científicos (MERTON, 2013, p. 159).

O conhecimento científico é (des)estimulado conforme os interesses e as estruturas sócio-institucionais. Desta forma, Merton destaca dois conjuntos de condições de hostilidades à ciência. $\mathrm{O}$ primeiro conjunto refere-se à lógica, ou seja, aos resultados e aos métodos hostis 


\section{Ensaios de sociologia da ciência: mais que uma coletânea, um mapa da visão mertoniana sobre ciência}

às satisfações de valores considerados importantes. O segundo conjunto é formado por elementos não lógicos, pois está relacionado à ideia de incompatibilidade entre os sentimentos compositores do éthos científico e os localizados em outras instituições. Ambos os conjuntos, de forma e intensidade variadas, participam das revoltas contra a ciência (2013, p. 160).

Merton utiliza o exemplo alemão do Terceiro Reich (vide: 2013, p. 162) no que diz respeito à estrutura institucional do conhecimento e seu emprego científico em prol do regime nazista, a fim de utilizá-lo em proveito do povo alemão. $\mathrm{O}$ autor ainda destaca as pressões sociais exercidas sobre a autonomia da ciência, que incidem no pesquisador de diversas formas. O cientista terá maior ou menor autonomia conforme o regime do Estado, se liberal ou totalitário, respectivamente (MERTON, 2013).

Merton destaca também a sujeição da ciência ao controle das instâncias institucionais e o repúdio a aplicação de normas utilitárias ao trabalho dos cientistas. Destaca ainda a repercussão negativa entre as pessoas pelos resultados socialmente reprováveis quando da utilização do conhecimento gerado pelos cientistas. Isso ocasiona uma responsabilização dos cientistas justamente pelo fato de que afeta a sociedade. $\mathrm{O}$ cientista não deve ignorar outros valores dos que aqueles circundantes ao puro conhecimento científico. É preciso que os cientistas levem em consideração, além do objetivo de alcançar o puro conhecimento, os efeitos perniciosos para a sociedade, assim como os valores sociais podem modificar o próprio éthos científico.

O cientista moderno tendeu a assumir uma distância considerável do leigo, a partir da exaltação da ininteligibilidade do conhecimento científico. Em termos de conhecimento, ao leigo resta aceitar, justamente pela especificidade do conhecimento como verdade, os argumentos que envolvem as descobertas científico-tecnológicas às quais o mesmo se beneficia. É preciso que toda conquista científica reverta-se em informações inteligíveis, capazes de serem compreendidas pelo senso comum. Outra questão invocada foi o ceticismo existente quando o conhecimento científico contraria valores e sentimentos básicos de outras instituições sociais e, por isso, acaba por sofrer resistência e revoltas e, por isso, acaba enfraquecido. Com efeito, em estruturas sociais liberais é possível se ter um grau de isolamento em relação à pesquisa cientifica, garantindo, deste modo, a autonomia de cada esfera da cultura humana e a integração gradual de elementos circunstancialmente inconsistentes (MERTON, 2013). 
O capítulo 7, o primeiro da terceira parte, intitulado "A ciência e a estrutura social democrática" - 1942 -, indica a necessidade de os cientistas repensarem a sua função diante dos novos desafios que têm surgido na sociedade moderna (e porque não, pós-moderna?). $\mathrm{O}$ éthos da ciência traz valores e normas que são considerados obrigatórios, porém não foram instituídos por legisladores. Foram forjados por artesãos ao longo dos anos e legitimados em termos de valores institucionais. Embora a autonomia científica perante as outras instituições sociais seja reconhecida, isso não significa seu isolamento, pois existe um grau de associação com a estrutura social (MERTON, 2013).

Ademais, Merton destaca as quatro características fundacionais do éthos científico, quais sejam: cosmopolitismo; universalismo; desinteresse; e ceticismo organizado. O escrito mertoniano trata-as como atitudes ou posturas a serem observadas pela comunidade científica, como se fossem normas, sendo importantes para a compreensão do status da ciência. O cosmopolitismo indica que as descobertas não se reduzem à esfera privada do cientista, mas à comunidade em geral, pois todos possuem a possibilidade de utilizá-las. O universalismo refere-se à validade do conhecimento, que deve ser calcada em critérios críticos e intelectuais, sem a interferência de elementos tendentes ao sectarismo, como a classe, a religião, a nacionalidade etc. $\mathrm{O}$ desinteresse corresponde à impessoalidade, ou seja, o cientista não deve ser movido pelo interesse pessoal, econômico, político ou de outro gênero, mas apenas buscar o conhecimento pelo conhecimento. O ceticismo organizado reporta-se à onipresença da crítica em face da validade do conhecimento científico, pois nenhuma alegação de autoridade pode sustentar uma verdade científica (MERTON, 2013).

O oitavo capítulo, denominado "O efeito Mateus na ciência II: a vantagem cumulativa e o simbolismo da propriedade intelectual" - 1988 -, consiste no desenvolvimento de um primeiro artigo publicado em 1962. A concepção mertoniana estabelece o "efeito Mateus" como a vantagem acumulativa em face às comparações. Significa que aquele que tiver mais créditos, mais receberá, já aquele que menos abundância tiver, terá, inclusive, retirado aquilo que possui - o primeiro livro do Novo Testamento, Evangelho segundo Mateus (13:12 e 25:29). Trata-se da arrecadação constante a partir de um reconhecimento, logo, esse reconhecimento influenciará a acumulação de reconhecimentos futuros (MERTON, 2013).

Ainda em relação ao "Efeito Mateus", a reputação conquistada convergirá em créditos de trabalhos desenvolvidos, a partir de algumas relações como número de citações, número de e qualidade das publicações em revistas científicas. Assim, os cientistas renomados atraem 


\section{Ensaios de sociologia da ciência: mais que uma coletânea, um mapa da visão mertoniana sobre ciência}

créditos ao ponto de cientistas de menor expressão serem desacreditados ou ignorados quando estão ao lado daqueles que são renomados, mesmo que os últimos pouco tenham contribuído. Nesse sentido, há a acumulação de vantagens e desvantagens pelos jovens e mais experientes cientistas, assim como entre as instituições científicas. Somam-se à acumulação processos compensatórios e o estabelecimento simbólico da propriedade intelectual (MERTON, 2013).

Frente a esta importante reunião dos principais escritos mertonianos, pode-se concluir que foi Merton quem, de fato - mesmo que Mannheim tenha contribuído de maneira ímpar à Sociologia do Conhecimento - sistematizou e consolidou a Sociologia da Ciência e a colocou na agenda intelectual da primeira metade do século XX. Isto ocorreu pela peculiaridade da epistemologia de Merton, ou seja, a ciência passara, desde então, a caracterizar-se como um campo autonomizado e institucionalizado, possuidor de suas normas e de seus valores, assim como o Estado, a Política, etc. Em outros termos, a identificação da ciência, do ethos científico, como instituição social, na qual se desenvolvem as normas que regem o comportamento científico (J.A.V.M, 2004) foi a grande contribuição de Merton para o desenvolvimento da Sociologia do Conhecimento, da Ciência e do Conhecimento Científico.

Assim, se por um lado Merton mostrou-se central para a compreensão da inextrincável relação estrutural entre ciência e sociedade, por outro não considerou a dimensão internalista da ciência. Em resumo, Merton não atentou para a explicação da dimensão epistemológica no que tange o núcleo-duro do conhecimento científico, ou seja, acabou por manter-se na marcante distinção de Reichenbach, entre contexto da descoberta e contexto da justificação, isto é, entre os aspectos de cunho social, político e econômico e a validação (epistemológica) do conhecimento cientifico. (ECHEVERRÍA, 2004). Tal cisão que, por seu turno, começa a “enfraquecer-se" a partir de Thomas Kuhn, com a "Estrutura das Revoluções Científicas", publicada em 1962. Ainda na década de 1960 e 1970 esta distinção interno/externo é mais criticada pelos esforços intelectuais do chamado Programa Forte da Sociologia (PF), representado, principalmente por David Bloor, Bruno Latour, Knor-Cetina, Henry Collins, entre outros, os quais apresentam como premissa o fato de que não é possível separar o contexto da descoberta do contexto da justificação quando observamos e estudamos os aspectos que influenciam a produção de conhecimento científico. 
NORUS - v3, n.4, jul-dez 2015.

\section{REFERÊNCIAS BIBLIOGRÁFICAS}

ECHEVERRÍA, Javier. El ethos de la ciência, a partir de Merton. In: VALERO, Jesús A (Org.). Sociología de la ciência. Santigo: EDAF ENSAYO, 2004. p. 31-56.

GARCIA, Sylvia Gemignani. Prefácio. In: MERTON, Robert K. Ensaios de sociologia da ciência. São Paulo: Associação Filosofia Scientiae Studia/Editora 34, 2013. p. 9-12

J.A.V.M . Presentación. In: VALERO, Jesús (Org.). Sociología de la ciência. Santiago EDAF ENSAYO, 2004. p. 9-12.

MARCOVICH, Anne; SHINN, Terry. Robert K. Merton, fundador da sociologia da ciência: comentários, insights, críticas. In: MERTON, Robert K. Ensaios de sociologia da ciência. São Paulo: Associação Filosofia Scientiae Studia/Editora 34, 2013. p. 253-272.

MERTON, Robert K. Ensaios de sociologia da ciência. São Paulo: Associação Filosofia Scientiae Studia/Editora 34, 2013. 